\title{
I mproving Thermal Conductivity and Fluid Loss Properties of Grouting Materials: New Mixed Grout Granules of Bentonites and Sands
}

\section{Kang Bai}

\begin{abstract}
We propose new granule type grouting materials with optimized ratio of bentonites and sands for use in the ground source heat pump systems. The grouting materials could be prepared in various size of 1.18 to $4.75 \mathrm{~mm}$. The granules consist of bentonite powders and sand particles inside and extra bentonite powders exists on the surface of granules. In different ratio (1:0-1:8) of bentonites and sands, the granules with 1:8 ratio show the best thermal conductivity (ca., $1.8 \mathrm{~W} / \mathrm{mK})$. In comparison to the existing powder type mixed grouting materials, the present granules show the lower values of fluid loss and the minimum values at 1:5 ratio of bentonites and sands. This might be due to the fact that the bentonites on the surface of granules strongly hold water, resulting in decrease of penetration of water into granules. We also investigated the effect of bentonites between the granules on fluid loss property by addition of them as slurry form. When only water is added, water channels were formed. When the slurry of bentonite and water is added, water channels were decreased, resulting from that the additional bentonites interacted with granules. According to aging time, the homogeneity of grouting layer is improved.
\end{abstract}

\section{NTRODUCTI ON}

Bentonite, discovered near Fort Benton region in Montana of Unite States in 1898 and named officially by Wilbur C. Knight, is one of the clay minerals. It has the incredible swelling ability in water and its volume can increase as much as about 20 times of its original volume. Since then, the bentonite has been well known for a brand name. Bentonite is part of the smectite class of clays that are less than 2 micrometers in largest dimension. It is a layered aluminum phyllosilicate, which consists mostly of the mineral montmorillonite produced in the Cretaceous period. (Ingleethorpe 1993) Nowadays, bentonite is used in different fields such as casting, engineering works, paper-making, feedstuff, and agriculture because it has various physico-chemical properties such as high swelling, high surface area, high ion exchangeability, high water adsorption, high surface charge and so on. (Ko 2000)

The grouting layer plays very important role in determining the overall efficiency of ground source heat pump systems due to the direct heat transfer from the ground materials to the heat exchangers. Among various grouting materials, bentonite has been widely used in ground source heat pump systems, because it is capable of not only holding water tightly due to its self-swelling property, but also preventing the migration of heat transfer layer due to its

Bai Kang (kabai@kier.re.kr) was research engineer at Korea Institute of Energy Research and established Bai International Corp. recently, and Taewoo-Kim is research engineer at Korea Institute of Energy Research. 
high viscosity (Park 2006). Nevertheless, the bentonite has a fatal weakness of low thermal conductivity (Salomone 1989). To improve it, sands have been utilized as an additive for increasing thermal conductivity. However, when the sands are added to bentonites, the excess contents of sands (ca., > 30\%) cause several problems such as the separation between bentonites and sands, the increase of fluid loss, and the failure of slurry pump blades. Therefore, it is known that sands of less than 30\% are suitable for use in actual grout slurry systems (Sohn 2006).

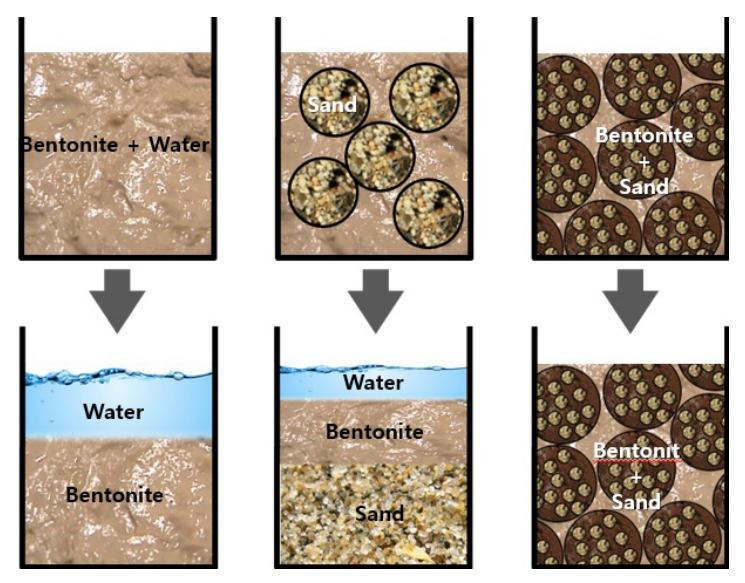

Figure 1 Concept of the mixed grout granules of bentonites and sands

In this work, we tried to overcome the problems mentioned above by forming the sands pre-mixed granules of bentonites as shown Figure 1. The effects of various factors, such as ratio of bentonites and sands, diameter of granules, and use of water or bentonite slurry, on thermal conductivity and fluid loss properties of the grouting materials prepared were systematically investigated. In addition, we revealed visually the change of microstructures of the mixed granule grout by using an optical microscope.

\section{EXPERI MENTS}

\section{Specimen Preparation}

As mentioned in introduction, bentonite can be easily swelled in water with plasticity. Using these properties, we prepared mixed granules by spraying water to bentonites and sands, and centrifugal force. Mixed ratio of bentonites (Barotherm Gold, Baroid Industrial Drilling Products Co) and sands (local product) was adjusted in the range of 1:0-1:8. The five different size granules from 1.18 to $4.47 \mathrm{~mm}$ were prepared by sieving separation (see Figure 2).

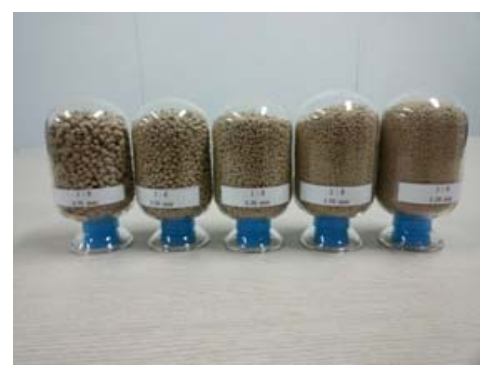

Figure 2 Mixed grout granules of bentonites and sands 


\section{Thermal Conductivity Measurements}

Thermal conductivity of bentonite was measured as a paste forms using non-steady-state probe (TP02, Hukseflux Co.) having two K-type thermocouples and a reference RTD (1) in Figure 3) inside. The measured data were collected using data logger (4) in Figure 3, CR 10X, Campbell Co.) with automatic scanning program (2) in Figure 3, Loggernet, Campbell Co.), and were calculated to thermal conductivity by software package (Hukseflux Co.), The measurements of thermal conductivity were performed in a temperature controlled chamber to maintain constant temperature of $25 \circ$.

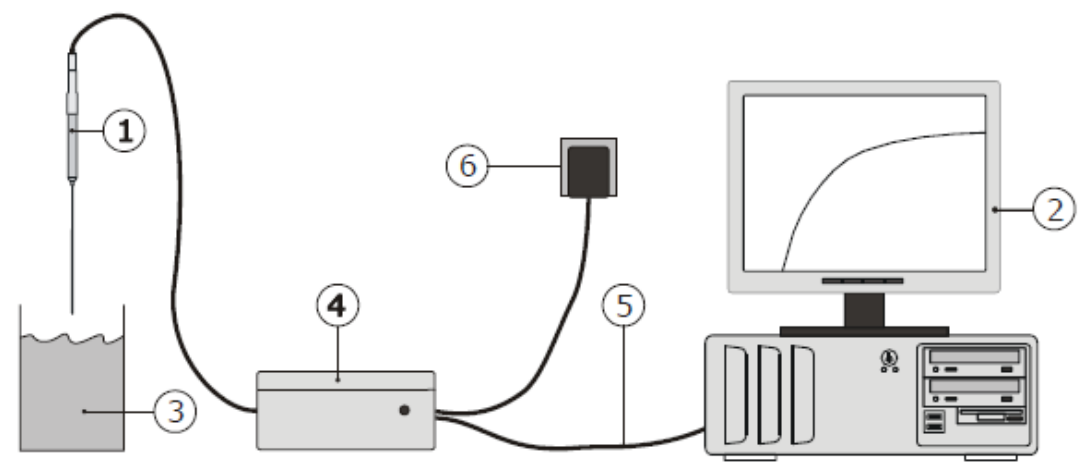

Figure 3 Measurement configuration of thermal conductivity for grouting materials (Hukseflux 2006) (1) TP02 Probe, (2) PC \& Software, (3) Specimens, (4) MCU(CR10X), (5) Communication Cable, (6) Power(DC12V)

\section{Fluid Loss Measurements}

Fluid loss test represents the water storage ability of bentonite. In the ground source heat pump systems, grouting layer plays an important role in protecting heat transfer layer from surface water or underground water. Typically, the fluid loss properties are tested by measuring amount of water passing through filter press paper in cylinder under $7 \mathrm{~atm}$. of nitrogen gas pressure until no water drop according to test method used in the companies generally. When amount of water become lower, water storage ability becomes better. In this work, we prepared two kinds of paste form specimens to reveal the effect of bentonites near granule boundary on fluid loss; (1) mixed granules + water, and (2) mixed granules + bentonites/waters slurry. Figure 4 shows the measurement apparatus (Filter Press API, Fann Co.) for fluid loss properties.

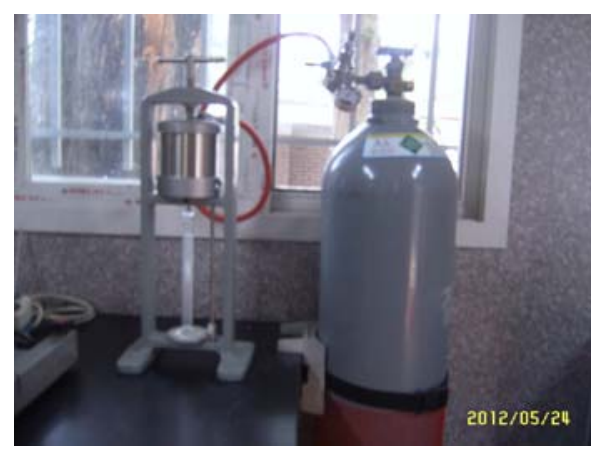

Figure 4 Measurement apparatus for fluid loss properties 


\section{RESULTS AND DI CUSSION}

\section{Thermal Conductivity Properties}

Figure 5-a) shows thermal conductivity change as a function of mixed ratio of bentonites and sands. Thermal conductivities of the present mixed materials show gradual increase with increase of sand content. This result shows similar to the previous results shown in existing powder-typed grouting materials. (Baroid Industrial Drilling Products, 2011) Also, we investigated thermal conductivity change as a function of granule sizes of mixed specimens with ratio of 1:3 (bentonite/sand). As plotted in Figure 5-b), thermal conductivity change on the different granule sizes shows below $10 \%$ in the range of 1.18 and $4.75 \mathrm{~mm}$, suggesting that the granule size does not affect thermal conductivity properties.
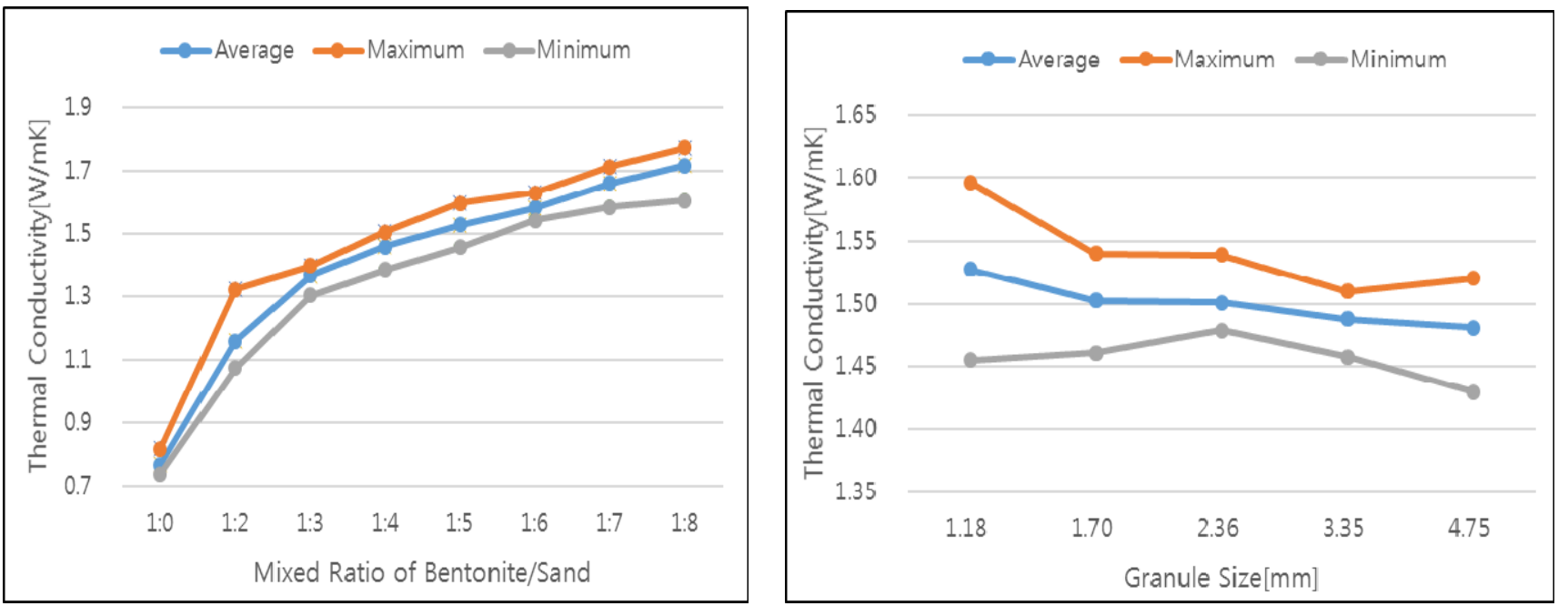

Figure 5 Thermal conductivity change with a) mixed ratio of bentonite/sand, b) granule sizes for mixed ratio 1:3 specimens of grout granules

\section{Fluid Loss Properties}

Figure 6 shows fluid loss property change as functions of a) ratio of bentonite/sand and b) granule sizes, respectively. As can be seen in Figure 6-a), fluid loss of the existing powder-typed grouting materials increase as increase of the amount of sands. This phenomenon means the decrease of water preventing performance as increase of the amount of water passed into bentonite layers due to high sand content. Interestingly, however, the mixed granules grouting materials show the gradual decrease of fluid loss in the range from 1:0 to 1:4 of bentonite/sand, and increase from ratio of 1:5. In order to find these reasons, microstructures of specimens were closely investigated. As can be seen in Figure 7, sands exist in granule inside and excess bentonites are placed on the surface of granules. In cases of over ratio of 1:5, it is thought that the bentonite content on the surface of granules is not enough and thus water channels gradually increase. Being used bentonite-water slurry instead of water, excess bentonites play a role in decreasing water channels. Therefore, it can be seen that the rate of increase of fluid loss is low. Also the fluid loss change on the different granule sizes shows below $10 \%$ in the range of 1.18 and $4.75 \mathrm{~mm}$ as shown in Figure 6-b), suggesting that the effect of granule sizes on fluid loss is relatively small. However, these values do not represent the actual circumstances in boreholes because the pressure is changed with depth mainly due to hydrostatic pressure differences, but it plays an important role as a comparative basis of water storage ability for grouting materials. 

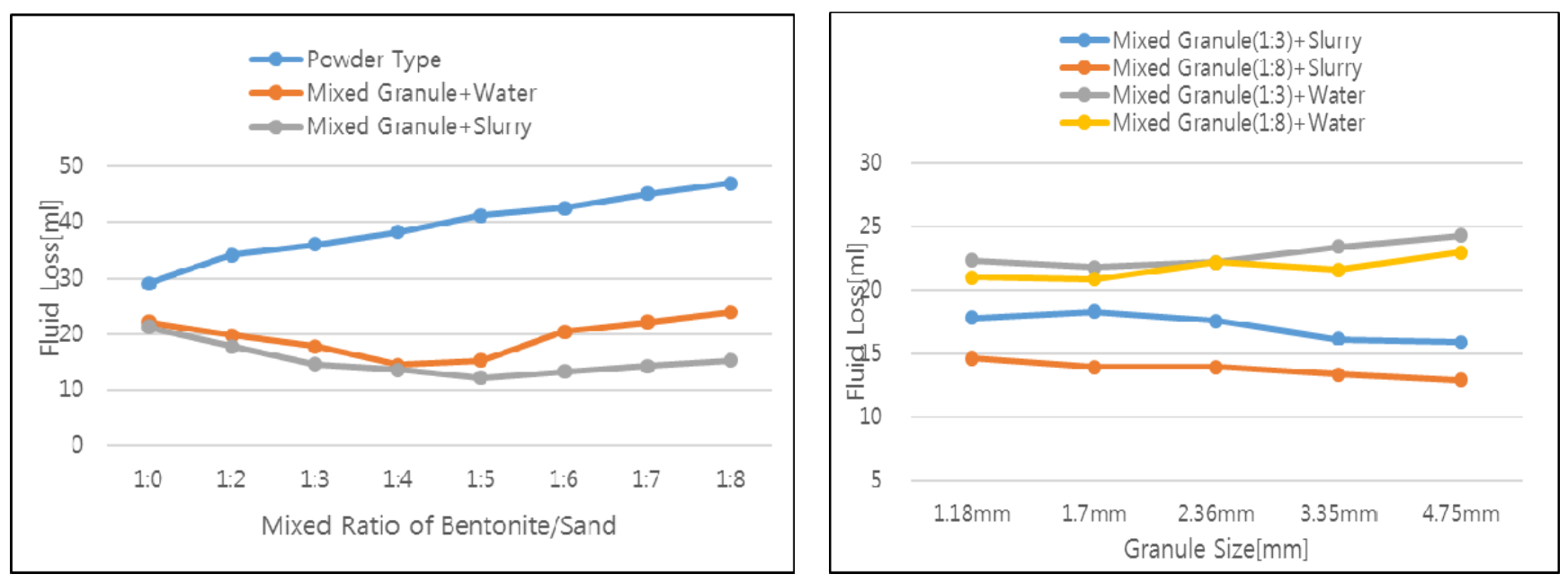

Figure 6 Fluid loss change with a) mixed ratio of bentonite/sand, b) granule sizes for mixed ratio 1:3 and 1:8 specimens of mixed grout granules

\section{Microstructures}

Figure 7 shows the photographs of fine structure of mixed granules prepared as a paste forms. When only water was added, water channel formed as shown in Figure 7-a). When water was used with bentonite, it could be seen that forming water channel decreased as shown in Figure 7-b). This can be explained by the fact that the granules are surrounded by bentonites and thus water is difficult to pass them. Consequently, the number of water channel formed between granules plays a role in determining the fluid loss ability. Meanwhile, it was not observed that there is separation phenomenon by adding excess sands.

X 12.5

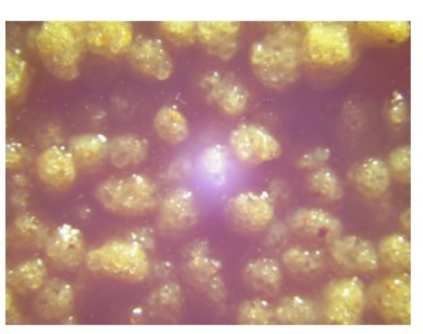

\section{Mixed Granules \\ + Bentonite \\ Slurry}

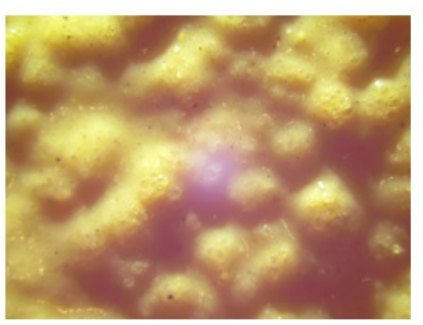

X 50
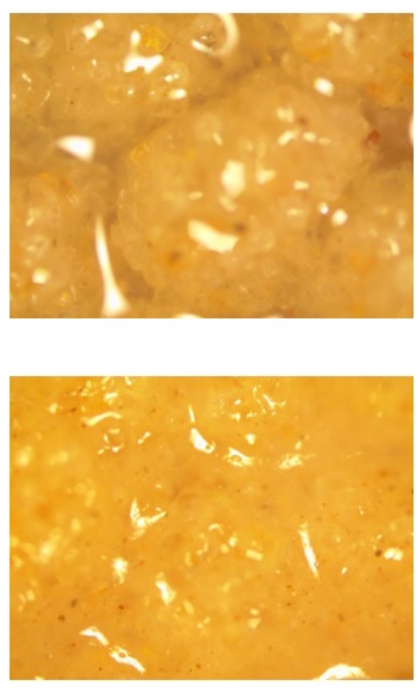

Figure 7 Microstructures of mixed grouting granules added a) only water, b) slurry of bentonites and waters 
Moreover, we monitored a change of microstructures of mixed granules according to aging time. As shown in Figure 8, it is gradually stabilized. In this reason, we can expect that the paste forms of mixed granules became stabilize, and forms uniform heat transfer layer with time.

$X 12.5$

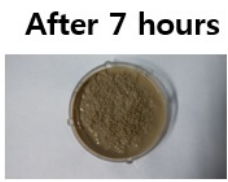

After 7 days

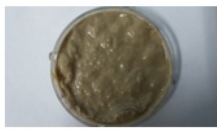

X 50
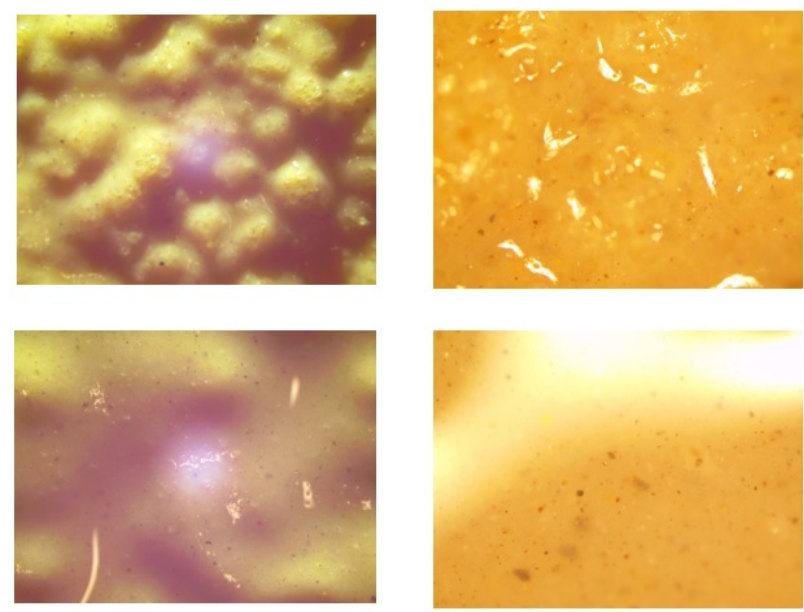

Figure 8 Stabilization process for mixed grout granules added slurry of bentonite and water

\section{CONCLUSION}

In this study, we investigated thermal conductivity and fluid loss properties of new grouting materials. It was prepared by pre-mixed granules of bentonites and sands. As we studied two properties of the grouting materials, the results were obtained as follows:

1. The fluid loss decreases to mixed ratio of 1:4(bentonite/sand), and then increases with the amount of sands increases from ratio of 1:5. In comparison with use of only water, the rate of increase in using slurry of bentonites and water is much lower. However, the fluid loss of existing powder type grouting materials increases steeply.

2. By investigating microstructures of granule-typed grouting materials, the gradual decrease of fluid loss might be due to the decrease of water channels presented in interfaces between granules. Additionally, it is gradually stabilized according to aging time and consequently a uniform grouting layer forms.

3. The thermal conductivity increases with sand content increases. This result is similar to that obtained from existing powder-typed grouting materials.

As a result, the mixed granule grouting materials show superior fluid loss properties to the existing powder type ones. This indicates that the former can be utilized with much more amount of sands than latter. Also, the fluid loss in specimen of ratio of 1:5 is the lowest and the thermal conductivity in specimen of $1: 8$ ratio increases up to $1.8 \mathrm{~W} / \mathrm{mK}$. Consequently, we can select the high content of sand granules, which means high thermal conductivity, on basis of the limited value of fluid loss for use in actual environment. Future work to measure the permeability of mixed granule grouting materials is still needed. 


\section{REFERENCES}

Baroid Industrial Drilling Products. 2011. BAROTHERM® GOLD Technical Note

Hukseflux Co. 2006. TPSYS02 Thermal Conductivity Measurement System USER MANUAL

Inglethorpe, SDJ, Morgan DJ, Highley, Bloodworth AJ 1993. Industrial Minerals Laboratory Manual BENTONITE, British Geological Survey

Ko, S.M, Lee, D.J, 2000. Present and Future of Bentonite Industrials, The 13th Proc. of J. Miner. Soc. Korea, 1-4(in Korean)

Park, S.W, Seo, J.H, Lee, S.H, 2006 Characteristics and Applications of Bentonites in Civil Engineering, J. Miner. Soc. Korea, 19, 1, 64-75 (in Korean)

Salomone, L.A. and Marlowe, J.I., 1989. Soil and rock classification for the design of ground-coupled heat pump systems: field manual, Special Report (EPRI CU-6600), Electric Power Research Institute

Sohn, B.H, Shin, H.J, 2006. Thermal Conductivity Measurement of Grouting Materials for Ground Heat Exchanger Borehole, Kor. J. Equip. Eng., 18, 6, 493-500(in Korean) 